\title{
Sciendo
}

HOLISTICA Vol 10, Issue 2, 2019, pp. 95-104

\section{High-speed railway and regional economic growth: a case of Beijing- Shanghai high-speed railway}

Yonghong, CHEN, Department of Economics, Shanghai University,Shanghai, China Address:No.20, Chengzhong Rd., Jiading District, Shanghai, China yhchen1995@163.com

\begin{abstract}
The development course of high-speed railway indicates that it not only changes the composition of traffic modes when competing with other modes of transportation, but also plays an important role in spurring the economic growth of the cities along the line and the evolution of regional spatial structure. Taking Beijing-Shanghai high-speed railway as an example, this paper constructs the first-level panel data of the cities along the Beijing-Shanghai high-speed railway and its surrounding cities from 2007 to 2016, and uses the difference-in-differences estimation to study the impact of high-speed rail opening on economic development. The research results show that it has significantly jump-started the economy of cities along the line. The Beijing-Shanghai high-speed railway will become a crucial axis for regional economic development along the Beijing-Shanghai railway, as it has remarkably advanced the economic development of the cities along the route.
\end{abstract}

Keywords: economic growth; high-speed railway; difference-in-differences

JEL Classification: D04; D4

\section{Introduction}

Every revolutionary breakthrough in transportation has a profound influence on city development, spatial evolution, as well as high-speed railways (HSR). Compared with other conventional means of transport, high-speed railway has many advantages, such as strong transport capacity, fast service speed, safety and reliability, punctuality and punctuality, land-and-energy saving, less environmental pollution, fewer traffic jams and accident troubles. As a set of an efficient transport system in a link, high-speed railway plays a vital role in the development of a city.

The development report of the World Bank (1994) pointed out that even if the infrastructure cannot be called the locomotive that affects economic activities, 
it is also the wheel to promote its development. Aschauer (1989) explores the relationship between infrastructure and economic growth and productivity, and since then more and more economists have focused on the relationship between infrastructure and economic growth. However, there are different opinions about the impact of high-speed railways on regional economic development.

Blum, Haynes and Karlsson (1997) argue that high-speed railways on the one hand may replace air transport, and on the other hand link new urban strips (or urban corridors) that are geographically separated from each other, and also promote economic integration within the region. Emilio et al. (2012) uses the GIS methods to find that the construction of high-speed rail corridors increased accessibility. The results show positive cohesion effects at the national and corridor levels, while balance and polarization effects appeared at the regional level. These differences are mainly caused by the location of the high-speed rail stations or the quality of the traffic network from the surrounding cities to the station. However, Roger (2015) discovers that the establishment of high-speed railway TEN-T has not yet reached the main goal of reducing regional differences in accessibility or reducing the impact of borders on regional integration by studying high-speed railways in Europe. Achieving this goal requires not only the provision of infrastructure but also an appropriate regulatory framework for services and corresponding measures at the local level. Puga (2008) also believes that high-speed rail benefits big cities and small cities suffer losses, thus exacerbating regional imbalances.

At present, regarding the relationship between China's high-speed railway and economic growth, Banerjee (2012) estimates the impact of the transportation network on China's regional economic results, which show that the proximity to the transportation network has a positive impact on per capita GDP, but has little relevance to per capita GDP growth. Andersson (2010) uses the characteristic price function of the residential property market to estimate the implied price of highspeed rail accessibility. The estimated results reveal that high-speed rail accessibility has little impact on housing prices. However, there are no latest articles that use the Beijing-Shanghai high-speed rail as a study for empirical analysis, and there are fewer articles using the difference-in-differences estimation (DID) to examine the economic effects of high-speed rail.

The Beijing-Shanghai high-speed railway connects China's financial center with political center - Shanghai and Beijing - and plays a pivotal role in China's economic construction. It was officially started on April 18, 2008 and opened to traffic on June 30,2011. The Beijing-Shanghai high-speed railway passes through the three municipalities directly under the Central Government of Beijing, Tianjin 
and Shanghai, and the four provinces of Jiangsu, Shandong, Anhui and Hebei. The total length of the Beijing-Shanghai high-speed railway is about 1,318 kilometers, with a total investment of $\mathbf{2 2 0 . 9}$ billion yuan and a design speed of 350 kilometers per hour.

An in-depth analysis of the economic effects of high-speed railways, along with an objective assessment of the contributions high-speed railways have made to regional economic development, plays an important role in speeding up regional economy growth. This paper does a quasi-natural experiment on BeijingShanghai high-speed railway, in order to construct the panel data of the cities which high-speed railway passes and those not passed, and the panel data before and after the opening of the high-speed rail. The difference-in-differences model is adopted to evaluate its impact on urban economic growth. The Differences-in Differences estimation is widely used in policy evaluation, which can control endogenousness to a certain extent and has a good evaluation effect.

\section{Methodology}

\subsection{Difference-in-Difference Estimation (DID)}

The Differences-in-Differences estimation was first proposed by Ashenfelter and Card (1984) when they study the income changes of particular project participants. As a powerful tool for policy effects evaluation, the difference-indifferences estimation is favored by more and more people. The reasons can be summarized as follows:

(1) It can avoid endogenous problems to a large extent: policy is generally exogenous to microeconomic subjects, so there is no reverse causal problem. In addition, the use of fixed-effect estimates also mitigates the problem of missing variable biases to some extent.

(2) Under the traditional method, the policy effect is evaluated mainly by setting a dummy variable for the occurrence or absence of a policy and then performing regression. In comparison, the difference-in-differences estimation is more scientific and can more accurately estimate the policy effect.

(3) The principle and model setting of the difference-in-differences estimation is very simple, easy to understand and use. So it is not as daunting as the method of spatial measurement.

The basic DID model settings are as follows:

$$
Y_{i t}=\alpha_{0}+\alpha_{1} d u+\alpha_{2} d t+\alpha_{3} d u \times d t+\varepsilon
$$


In this model, $d u$ is a group dummy variable. If the individual $i$ is affected by the policy implementation, the individual $i$ belongs to the treatment group, and the corresponding $d u$ takes the value 1 . If the individual $i$ is not affected by the policy implementation, the individual $i$ belongs to the control group, and the value of $d u$ is 0 . $D t$ is a dummy variable for policy implementation. Before the policy implementation, $d t$ takes a value of 0 . After the policy is implemented, $d t$ takes a value of 1 . Du.dt is the interaction term between the dummy variable and the policy implementation dummy variable, and its coefficient reflects the net effect of policy implementation.

Table 1. The DID estimator

\begin{tabular}{cccc}
\hline & $\begin{array}{c}\text { Before policy } \\
\text { (dt=0) }\end{array}$ & $\begin{array}{c}\text { After policy } \\
\text { (dt=1) }\end{array}$ & Difference \\
\hline $\begin{array}{c}\text { Treatment group } \\
\text { (du=1) } \\
\begin{array}{c}\text { Control group } \\
\text { (du=0) }\end{array}\end{array} \alpha_{0}+\alpha_{1}$ & $\alpha_{0}+\alpha_{1}+\alpha_{2}+\alpha_{3}$ & $\alpha_{2}+\alpha_{3}$ \\
Difference & $\alpha_{0}$ & $\alpha_{0}+\alpha_{2}$ & $\alpha_{2}$ \\
\hline
\end{tabular}

\subsection{Model settings and variables}

This paper mainly examines the role of high-speed rail in promoting urban economic growth. As a policy shock, high-speed rail can use DID estimation to measure the role of high-speed rail opening. Specifically, the city through which the Beijing-Shanghai high-speed railway passes can be used as an treatment group. And the cities which the Beijing-Shanghai high-speed railway does not pass through but belongs to the same province can be used as a control group. The regression equation can be written as:

$$
Y_{i t}=\alpha+\alpha_{u} d u+\alpha_{t} d t+\alpha_{d i d} d u \times d t+\varepsilon
$$

In this equation, $D u=0,1$ are the cities that the Beijing-Shanghai high-speed railway passes through and the cities that the Beijing-Shanghai High-speed railway does not pass through. $D t=0,1$ respectively indicate before and after the opening of the Beijing-Shanghai high-speed railway. Therefore, all samples are divided into four groups from two dimensions: the treatment group and the control group before and after the opening of the Beijing-Shanghai Railway. In this regression equation, the estimated coefficient $\alpha_{\text {did }}$ of the product term of two dummy variables is of most concern to us. When the sample points belong to the treatment group and go through the opening of the Beijing-Shanghai high-speed 
railway, we will see $d u_{i t} \times d t_{i t}=1$, so the $\alpha_{\text {did }}$ measures the net impact of railway speed increase on economic growth.

According to the growth theory, the factors affecting economic growth are material capital, human capital, labor, technical level, etc. In addition to this, we should take other control variables in consideration. Considering the availability of data and other factors, the final regression model is based on MODEL (2) :

$$
\begin{aligned}
& Y_{i t}=\beta_{0}+\beta_{1} d u_{i t} \times d t_{i t}+\beta_{2}\left(n_{i t}+\gamma+\delta\right)+\beta_{3} \ln p g d p_{i t}+\beta_{4} \ln _{\text {save }}+\beta_{5} \ln g o v_{i t}+ \\
& \beta_{6} \text { ln health }_{i t}+\alpha_{i}+\gamma_{t}+\varepsilon_{i t}
\end{aligned}
$$

Subscript $i$ represents the city and $t$ represents time. $Y$ represents the rate of economic growth, which is expressed in terms of GDP growth rate per capita in this paper. Another part of the formula, $n+\gamma+\delta$, represents the revised population growth rate, where $\delta$ and $\gamma$ represent the capital depreciation rate and the technological progress rate respectively. According to Xu et al. (2007), $\gamma$ and $\delta$ can be taken as $0.1(\gamma+\delta=0.1)$.

Lnpgdp indicates the income of each city at the beginning of each period, expressed in logarithm of GDP per capita.

Lnsave represents the savings rate. For China's urban-level savings rate, this paper uses the proportion of fixed-asset investment in GDP in that year.

Lngov represents the logarithm of fiscal expenditure as a percentage of GDP and is used to control how much a city depends on government-driven economic growth. This variable is also used to control government intervention in the literature on economic growth.

Lnhealth is the logarithm of the number of hospital beds per capita. Because of the lack of direct measures, this variable is used to control the human capital of health dimension.

$\alpha$ is the urban fixed effect, $\gamma$ is the time fixed effect. In this paper, the dummy variables are taken for each year from 2006 to 2016. To avoid endogeneity, only the nine variables from 2008 to 2016 are generated. And $\varepsilon$ is a random error term.

\subsection{The treatment group and the control group}

The Differences-in-Differences estimation has strict preconditions, which the treatment group and the control group are required to have no difference before the experiment. The difference after the experiment is only caused by the experimental variables, which is caused by the high-speed rail opening in this 
paper. Therefore, this paper selects the cities similar to the treatment group as much as possible when selecting the control group.

The Beijing-Shanghai high-speed rail has 24 stops and stops in 19 cities. Considering the particularity of cities, this paper chooses the two provinces that have the most cities passed by Beijing-Shanghai high-speed rail - Shandong Province and Jiangsu Province. There are 17 prefecture-level cities in Shandong Province. Among them, there are 5 prefecture-level cities passed by BeijingShanghai high-speed rail, which is Dezhou, Jinan, Tai'an, Jining, Zaozhuang. Since Jinan is the provincial capital, it is excluded from the treatment group. Among the remaining 12 prefecture-level cities, cities that are far from the Beijing-Shanghai high-speed rail line and are seaports, such as Yantai, Rizhao, Qingdao, and Weihai, are excluded. The remaining 8 cities are excluded as the control group.

Similarly, there are 13 prefecture-level cities in Jiangsu Province. Among them, there are six cities through which the Beijing-Shanghai high-speed railway passes: Xuzhou, Nanjing, Zhenjiang, Changzhou, Wuxi, and Suzhou. After dropping the provincial capital of Nanjing, it is necessary to eliminate the higher level of economic development of Suzhou and Wuxi (because the economic development level of these two cities is much higher than other cities.). There are seven prefecture-level cities in which the Beijing-Shanghai high-speed rail does not pass. Because Lianyungang is far from the Beijing-Shanghai high-speed railway and is a seaport city, it is removed. The remaining six cities are relatively close, and they are treated as control groups. The selection of treatment and control groups is shown in Table 2.

Table 2. The treatment group and the control group

\begin{tabular}{cc}
\hline The treatment group & The control group \\
\hline Shandong Province: Dezhou, Taian, Jining, & Shandong Province: Liaocheng, \\
Zaozhuang & Heze,Bingzhou, Dongying, Zibo, Laiwu, \\
Weifang, Linyi
\end{tabular}

\section{Data collection and descriptive statistics}

The data in this paper is based on the urban panel data established in the 2007-2016 China Urban Statistical Yearbook. Based on the 2000 year, the CPI index is used to adjust the GDP to obtain the actual GDP. As the official opening date of the Beijing-Shanghai high-speed railway is June 30, 2011, this paper defines the 
period of time before which, from 2006 to 2011, as the non-HSR age, and the time after then, from 2012 to 2016 as the HSR age.

The descriptive statistics of the main explanatory variables and the explained variables are illustrated in Table 3. The sample includes the GDP of 21 cities during 2007 and 2016 in total. Due to the missing data of some cities in some years, the number of observations is partially influenced. As can be seen from Table 3, the data difference between the treatment group and the control group is not large.

Table 3. Descriptive statistics of interpreted and explanatory variables

\begin{tabular}{cccccccc}
\hline & Variables & $\mathbf{y}$ & $\mathbf{n}$ & Inpgdp & Insave & Ingov & Inhealth \\
\hline & $\max$ & 2.56 & 38.90 & 11.77 & 1.99 & 0.61 & 10.82 \\
The entire & $\min$ & 1.00 & 3.19 & 8.91 & 1.83 & 3.51 & 8.32 \\
sample & $\operatorname{mean}$ & 0.15 & 5.38 & 10.43 & 0.20 & 2.00 & 9.84 \\
& $\mathrm{sd}$ & 0.31 & 5.67 & 0.52 & 0.35 & 0.40 & 0.52 \\
& $\mathrm{~N}$ & 209 & 210 & 209 & 208 & 209 & 210 \\
\hline \multirow{2}{*}{ The } & $\mathrm{max}$ & 2.56 & 21.90 & 11.46 & 0.49 & 1.61 & 10.80 \\
treatment & $\min$ & 0.64 & 3.19 & 9.66 & 0.97 & 2.66 & 9.00 \\
group & $\operatorname{mean}$ & 0.16 & 5.40 & 10.53 & 0.21 & 2.09 & 9.85 \\
& $\mathrm{sd}$ & 0.36 & 5.19 & 0.44 & 0.27 & 0.26 & 0.47 \\
& $\mathrm{~N}$ & 70 & 70 & 70 & 70 & 70 & 70 \\
\hline \multirow{2}{*}{ The } & $\mathrm{max}$ & 2.26 & 38.90 & 11.77 & 1.99 & 0.61 & 10.82 \\
control & $\mathrm{min}$ & 1.00 & 2.67 & 8.91 & 1.83 & 3.51 & 8.32 \\
group & $\mathrm{mean}$ & 0.15 & 5.37 & 10.38 & 0.20 & 1.96 & 9.83 \\
& $\mathrm{sd}$ & 0.28 & 5.91 & 0.55 & 0.38 & 0.45 & 0.55 \\
& $\mathrm{~N}$ & 139 & 140 & 139 & 138 & 139 & 140 \\
\hline
\end{tabular}

\section{Results}

\subsection{Basic results}

In this paper, the fixed effect model is used to control the urban fixed effect. The virtual variables of the year are added into the regression model to control the fixed time effect, and the Coefficient of the interaction should be the effect of pure HSR. As shown in Table 4, the coefficient of didt is significantly positive, consistent with expectations. 
Table 4. The empirical result

\begin{tabular}{cccccc}
\hline Variables & $\mathbf{( 1 )}$ & $\mathbf{( 2 )}$ & $\mathbf{( 3 )}$ & $\mathbf{( 4 )}$ & $\mathbf{( 5 )}$ \\
\hline didt & $\mathbf{g}$ & $\mathbf{a g}$ & $\mathbf{a g}$ & ag & ag \\
& $0.194^{* * *}$ & $0.186^{* * *}$ & $0.220^{* * *}$ & $0.0877^{* *}$ & $0.0726^{* *}$ \\
$\mathbf{n}$ & $(0.0711)$ & $(0.0684)$ & $(0.0539)$ & $(0.0394)$ & $(0.0311)$ \\
& -0.000157 & -0.000109 & -0.00199 & -0.00217 & -0.00300 \\
Inpgdp & $(0.00521)$ & $(0.00502)$ & $(0.00438)$ & $(0.00326)$ & $(0.00256)$ \\
& $1.247^{* * *}$ & $1.204^{* * *}$ & $1.066^{* * *}$ & $0.843^{* * *}$ & $0.812^{* * *}$ \\
Insave & $(0.106)$ & $(0.102)$ & $(0.0822)$ & $(0.0609)$ & $(0.0524)$ \\
& $0.181^{* *}$ & $0.176^{* *}$ & 0.0947 & 0.0544 & 0.0387 \\
Ingov & $(0.0821)$ & $(0.0790)$ & $(0.0633)$ & $(0.0495)$ & $(0.0418)$ \\
& -0.101 & -0.1000 & -0.0761 & -0.0414 & 0.00519 \\
Inhealth & $(0.0923)$ & $(0.0888)$ & $(0.0777)$ & $(0.0638)$ & $(0.0555)$ \\
& -0.212 & -0.208 & -0.229 & 0.0251 & -0.0208 \\
Cons. & $(0.207)$ & $(0.199)$ & $(0.158)$ & $(0.101)$ & $(0.0838)$ \\
& $-10.63^{* * *}$ & $-10.29 * * *$ & - & $-8.596 * * *$ & $-7.758^{* * *}$ \\
& $(2.165)$ & $(2.083)$ & $(1.675)$ & $(1.140)$ & $(0.945)$ \\
\hline Time fixed effect & Yes & Yes & Yes & Yes & Yes \\
City fixed effect & Yes & Yes & Yes & Yes & Yes \\
Obs. & 207 & 207 & 297 & 457 & 595 \\
R2 & 0.496 & 0.487 & 0.437 & 0.367 & 0.353 \\
Number of cities & 21 & 21 & 30 & 46 & 60 \\
\hline
\end{tabular}

Standard errors in parentheses $* * * p<0.01,{ }^{* *} p<0.05, * p<0.1$

The $y$ in column (1) is the nominal GDP growth rate, and the $y$ in column (2) is the real GDP growth rate. Observing the regression results of the first two columns, we can see that there is no significant difference in the impact of HSR on nominal GDP growth rate and reagent GDP growth rate, and high-speed rail can promote the economic development of cities along the route. There are several reasons for why high-speed rail will promote urban economic development: (1) High-speed railway is one of the transportation infrastructure.

The construction process of transportation infrastructure is a process of inputting resources and capital. It will form investment demand for other industries in the national economy, which will drive or drive related industries to drive the overall economic growth. (2) High-speed railway, whose construction and operation will promote the growth and development of the transportation industry, is an important part of economic growth and makes direct contributions to it. (3) The completed high-speed railway can provide transportation services for 
the economy, improve the efficiency of the transfer of various economic factors, promote the improvement of all-factor production efficiency, and thus promote economic growth. At the same time, due to the improvement of transportation conditions, it will also enhance the location advantages along the line, and promote the sustainable development of the regional economy.

\subsection{Robustness test}

In order to examine whether the choice of control group and treatment group will have different effects on the empirical results, the control group and the experimental group were re-selected in the robustness test (See Table 4, columns 3-5). First, the cities that are originally removed from Jiangsu Province and Shandong Province are added and returned. It is found that the regression coefficient is still significantly positive and the value is improved. Then Anhui Province is added, and the results do not change significantly.

Finally, all the cities with stations on the Beijing-Shanghai high-speed railway are treated as treatment group, while other cities in the same province that do not have stations on the Beijing-Shanghai high-speed railway served as control group. This approach is relatively lax, but the results show that the impact of high-speed rail on urban economic development is still a significant boost.

\section{Conclusion and discussion}

This paper has verified the impact of high-speed railway on urban economic growth through the case study of Beijing-Shanghai high-speed railway, the construction of differences-in-differences estimation and the analysis of the panel data of 60 Chinese cities from 2007 to 2016, among which cities without highspeed railway stations are organized as control group, and the cities with highspeed railway stations as treatment group.

The empirical results show that the HSR can significantly improve the GDP growth rate of the cities along the line and promote the economic development of these cities. This is mainly because the construction of Beijing-Shanghai HighSpeed Railway requires huge investment, and also can promote domestic demand, bring business opportunities and promote the development of related industries. The Beijing-Shanghai High-Speed Railway has to meet not only the transport needs of Beijing and Shanghai, but also the demands of those cities along the highspeed railway; hence the HSR leads to production increase, employment expansion, and the regional development along the route.

But it is undeniable that regional economic development is influenced by multiple factors in real situations, so traffic conditions is only one of them, and it 
is not the dominant one under most cases. From the extensive practical experiences of the development of high-speed railway in foreign countries, the impact of high-speed rail on the regional economy is constrained by many factors, and it usually does not create favorable or unfavorable conditions for the region itself. Its role is to amplify the favorable or unfavorable factors that exist.

Therefore, it is necessary for us to both realize the positive effects of BeijingShanghai high-speed rail on promoting the economic development of cities along the line without exaggeration, and fully understand the possible negative effects and other issues which might as well be avoided or minimized as much as possible. Only in this way can HSR really contribute to the economic development of the cities along the line.

\section{References}

[1] Andersson, D.E., Shyr, O.F., \& Fu, J. (2010). Does high-speed rail accessibility influence residential property prices? Hedonic estimates from southern Taiwan [J]. Journal of Transport Geography, 18(1), pp. 0-174.

[2] Aschauer, D.A. (1989). Is Public Expenditure Productive?, Journal of Monetary Economics, 23(2), pp. $177-200$.

[3] Ashenfelter, O., \& Card, D. (1984). Using the longitudinal structure of earnings to estimate the effect of training programs [J]. Review of Economics\&Statistics, 67(4), pp. 648-660.

[4] Banerjee, A.V., Duflo, E., \& Qian, N. (2012). On the Road: Access to Transportation Infrastructure and Economic Growth in China [J]. Social Science Electronic Publishing, 11(1), pp. 1-53.

[5] Blum, U., Haynes, K.E., \& Karlsson, C. (1997). Introduction to the Special Issue: The Regional and Urban Effects of High speed Trains [J], The Annals of Regional Science, 31(1).

[6] Ortega E., López, E., \& Monzón, A. (2012). Territorial cohesion impacts of high-speed rail at different planning levels [J]. Journal of Transport Geography, 24(Complete), pp. 130-141.

[7] Pollutants, P.A. (1994). World development report 1994: infrastructure for development. Executive summary. [J]. Washington D, 29(100), p. 53.

[8] Puga, D. (2008). Agglomeration and Cross-Border Infrastructure [J]. EIB Papers, 13, (2), pp. 102-124

[9] Vickerman, R. (2015). High-speed rail and regional development: the case of intermediate stations [J]. Journal of Transport Geography, 42, pp. 157-165.

[10] Xu X., \& Wang, X., \& Shu, Y. (2007). Local Officials and Economic Growth: Evidence from the Exchange of Chinese Governors and Provincial Party Secretaries [J]. Economic Research, (9), pp. 18-31. 